\title{
THE WORK OF THE MATHEMATICIAN LEOPOLDO NACHBIN (1922-1993) FROM FNFI
}

\author{
Clovis Pereira da Silva \\ Curitiba - PR, Brasil \\ (aceito para publicação novembro de 2019)
}

\begin{abstract}
In this paper we discuss the professional activity of Leopoldo Nachbin (1922-1993) in the period in which he worked at National Faculty of Philosophy of the University of Brazil (FNFi/UB, in Portuguese) until his retirement by Institute of Mathematics of the Federal University of Rio de Janeiro (IM/UFRJ, in Portuguese). We identify the influence played by some mathematicians such as G. Mammana (1893-1980), L. Schwartz (1915-2002), A. Monteiro (1907-1980), A. Weil (1906-1998), J. Dieudonné (1906-1992), M. Stone (19031989), and A. A. Albert (1905-1972) in the professional training of L. Nachbin. We also address the serious difficulties he encountered in the Mathematics Department of FNFi when he was entered in the competition, opened in 1950, for the post of full Professor (Professor Catedrático) of Mathematics and Superior Analysis of FNFi. We emphasize in the paper, that the period from 1947 to the 1960s marks the most creative and productive phase in terms of scientific research in the academic life of L. Nachbin.
\end{abstract}

Keywords: Leopoldo Nachbin, Mathematical Analysis, FNFi, Brazilian mathematical community.

\section{[O Trabalho do MATEMÁtico LeOPOLdo NACHBin (1922-1993) A PARTIR DA FNFi]}

\section{Resumo}

Neste artigo abordamos a atividade profissional de Leopoldo Nachbin (1922-1993) no período em que ele trabalhou na FNFi da UB e no IM/UFRJ, até sua aposentadoria pelo IM/UFRJ. Identificamos a influência desempenhada por alguns matemáticos como: G. Mammana (1893-1980), L. Schwartz (1915-2002), A. Monteiro (1907-1980), A. Weil (1906-1998), J. Dieudonné (1906-1992), M. Stone (1903-1989), A. A. Albert (1905-1972) na formação profissional de L. Nachbin. Versamos também sobre as sérias dificuldades por ele enfrentadas no Departamento de Matemática da FNFi, quando de sua inscrição no concurso, aberto em 1950, para o cargo de Professor Catedrático da Cátedra Análise Matemática e Superior da FNFi. Ressaltamos no artigo que, o período que vai de 1947 aos 
anos 1960 marca a fase mais criativa e produtiva, em termos de pesquisa científica, na vida acadêmica de L. Nachbin.

Palavras-chave: Leopoldo Nachbin, Análise Matemática, FNFi, comunidade matemática brasileira.

\section{Introduction}

The objective of this paper is to make an approach on the professional activity of the Brazilian mathematician Leopoldo Nachbin (1922-1993), during the period in which he worked at the National Faculty of Philosophy of the University of Brazil (FNFi/UB, in Portuguese) and at the beginning of the Institute of Mathematics from the Federal University of Rio de Janeiro (IM/UFRJ, in Portuguese). This period goes from 1947 until the date of his retirement at UFRJ, which occurred in $1982^{1}$.

L. Nachbin developed, from the FNFi/UB, an intense and profitable professional life publishing several papers and books, besides teaching classes for undergraduate and graduate courses, to organize, together with prof. dr. Luis Adauto da Justa Medeiros, the program of graduate of the newly created IM/UFRJ in the early 1970s, to guide seminars, to stimulate and organize scientific events in Mathematical Analysis, to guide Brazilian and foreign students. Due to L. Nachbin's prestige with the international mathematical community, and with several contacts abroad, he also sent several talented young students to do their Ph.D. in excellent foreign universities. Among these young students we mention Luis Adauto da Justa Medeiros and Mário C. Matos.

In addition to the above, our analysis also reveals the emerging dynamics of postWorld War II international mathematics; dynamics in which L. Nachbin immersed and shows how some scientists and some mathematical theories gained prominence in this period. For example, in the period between 1947 and 1950, Laurent Schwartz (1915-2002) ceased to be an almost unknown mathematician outside France, to be an international mathematical celebrity, culminating in 1950 when he was awarded the Fields Medal during the ICM-1950, held in Cambridge, Massachusetts, USA, received the prize for his work in theory of distributions, a topic he worked on from 1944. After 1950, the theory of distributions was studied by Brazilian scientists who worked in institutions based in the axis São Paulo - Rio de Janeiro. Other mathematical creative stood out internationally after 1945, among them André Weil (1906 - 1998), Jean Dieudonné (1906 - 1992), members of the N. Bourbaki group ${ }^{2}$. The great advances of Mathematical Analysis in Brazil during the 1950s, 1960s and 1970s of the twentieth century are to a predominantly large extent associated with the pioneering work of L. Nachbin. This holds true to a special degree for L. Nachbin, who most successfully introduced a new level of teaching strongly oriented to their current research.

\footnotetext{
${ }^{1}$ After this date L. Nachbin returned to work at CBPF as full professor.

${ }^{2}$ A. Weil stood out with important results obtained in number theory and in algebraic geometry. J. Dieudonné excelled with important works produced in abstract algebra and functional analysis.
} 
While few Brazilian mathematicians who stood out for their pioneering work in the twentieth century were honored, via more or less detailed biographies, a similar account of L. Nachbin's life and work has not yet been made. This text intends to be the first attempt to remedy this situation, focusing only on the work of L. Nachbin.

\section{Contextual Elements}

Around 1930 the conditions to study mathematics in Brazil were fairly bad for students really deeply interested in the subject. Still as a student of the engineering course of the National School of Engineering of the University of Brazil, in Rio de Janeiro (ENE/UB, in Portuguese), in which he joined in 1939, L. Nachbin asked for permission to attend lectures as a guest student at the $\mathrm{FNFi} / \mathrm{UB}$, and approached the Italian mathematician Gabriele Mammana (1893 - 1980) who had been hired in 1940 as a visiting professor to the Department of Mathematics of FNFi/UB, and also approached the theoretical physicist Luigi Sobrero (1909 - 1979), another Italian professor who had been hired as a visiting professor to the Department of Physics of FNFi/UB. Informally, L. Nachbin attended, as a listening student, the lessons of some of the courses that were taught at FNFi by these two Italian professors. He also attended seminars led by them. It should be remembered that, at this time, federal legislation concerning higher education forbade a student to enroll simultaneously in two undergraduate courses at the same university.

G. Mammana was an analyst specializing in Calculus of Variations. He had been contracted to govern the Chair (Cátedra) of Mathematical Analysis and Superior of the Department of Mathematics of the FNFi; he and L. Sobrero realized the talent of L. Nachbin for studies and research in Mathematics, which in turn was interested in studies in Mathematical Analysis and started to perform research and write papers in this subarea of Mathematics.

The first papers published by L. Nachbin in the Annals of the Brazilian Academy of Sciences and in other journals, for example, the paper: Sobre a permutabilidade entre operações de passagem ao limite e de integração de equações diferenciais. An. Acad. Bras. Ciênc., tomo. 13, p. 327-335, 1941. G. Mammana presented this paper to ABC in a session held on August 7, 1941. In paper L. Nachbin used ideas of Functional Analysis.

In the introduction of this paper the author was expressed:

"In this note we wish to establish a theorem relating to successions of normal differential equations. The question to which this theorem refers can be presented in the following terms:

A theorem is known, due to Arzelá, concerning the passage to the boundary under the integration signal. This theorem ${ }^{3}$, generally stated as follows:

Theorem of Arzelá. If $f_{l}(x), \ldots, f_{p}(x), \ldots$ denotes a convergent sequence of continuous and balanced functions simultaneously defined in the interval

\footnotetext{
${ }^{3}$ Theorem that is stated on page 330 of the paper.
}

RBHM, Vol. 19, no 38, p. 83-103, 2019 
$\left(x^{\prime}, x^{\prime \prime}\right)$ whose boundary function, $f(x)$, is continuous, the numerical succession converges

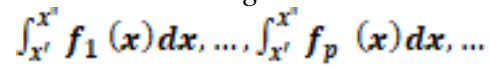

and its limit is given by the relation

$$
\lim _{p \rightarrow \infty} \int_{x^{\prime}}^{x^{\prime \prime}} f_{p}(x) d x=\int_{x y}^{x^{\prime \prime}} f(x) d x .
$$

Arzelá's theorem thus formulated naturally suggests the question: Is it possible to extend to differential equations of a more general type the preceding result on the differential equations of the very simple type mentioned?

It is of such an extent that I will deal with it here. To the above considerations I was taken, last year, when I dealt with the question, of didactic interest, to me proposed by Professor G. Mammana, of the demonstration, with elementary means, of the mentioned theorem of Arzelá; and it was under his promptings that I completed the wording of this note”. (NACHBIN, 1941).

In pages 328 and 329 of the paper in question, L. Nachbin states precisely the question concerning the differentiable equations that are suggested by Arzelá's theorem and says:

"Under what conditions is it possible to ensure the convergence, at least in $A\left(A=\left(a^{\prime}, a^{\prime \prime}\right)\right)$ of the succession of functions $\left\{f_{p}(x)\right\}$ for the function $f(x)$ ?

This is the question we wish to study. We will give this question a solution by establishing a set of sufficient conditions under which, as is customary to say, the operations of crossing over and integrating differential equations become interchangeable”. (NACHBIN, 1941).

This time L. Nachbin was 19 years old. Another paper in this phase is the following: Un estensione di un lemma di Dirichlet. Atti. Accad. Italy Rend., vol. 3, p. 204 208, 1942. The publication of this paper was sponsored by L. Sobrero. To write this paper L. Nachbin was motivated by Harmonic Analysis ${ }^{4}$.

With the entrance of Brazil in World War II, in 1942, the Italian professors mentioned above had their work contracts terminated and returned to Italy.

From an early age L. Nachbin has shown strong interest in the studies of Mathematical Analysis, especially in the studies of Topology and Functional Analysis. But because he did not have a degree in mathematics, L. Nachbin had serious difficulties early in his career as a professor of mathematics at FNFi/UB. In this paper we will give

\footnotetext{
${ }^{4}$ It should be remembered that in 1952 J. Dieudonné, then visiting professor in the Department of Mathematics at FNFi, taught a course on Harmonic Analysis. To the interested reader consult Dieudonné (1952). See also on this topic Nachbin (1949b). We do know that L. Nachbin, besides his courses, devoted himself to a deep private study of J. Dieudonné' works, and L. Schwartz' works.
} 
some information about the complicating effects for L. Nachbin's professional life at FNFi/UB.

After the end of World War II in 1945, the Mathematics Department of FNFi contracted as visiting professor the Portuguese António A. Monteiro (1907 - 1980), a mathematician who had studied in Paris and was current with the emerging mathematics of post-World War II. In his classes and in seminars organized by António Monteiro he began to teach topics such as: ordered sets, lattices and Boolean algebras. Current affairs for that time and that attracted the attention of L. Nachbin who approached António Monteiro from whom he became a close friend. At this stage, L. Nachbin acquired the taste for ordered, reticulated sets and Boolean algebra. Nachbin made rapid progress in mathematics under Monteiro's guidance and by his diligent private study of mathematical treatises, such that he acquired an unusually broad knowledge even at this early age.

At the suggestion of António Monteiro, who encouraged him to study the above mentioned areas and, as there was at the time, a theorem of the mathematician Marshall Stone for a Boolean algebra, stating that "an ideal is maximal if and only if it is prime", see Stone (1937), António Monteiro suggested to L. Nachbin the solution of a reciprocal question for the Marshall Stone theorem.

Thus, in 1947, L. Nachbin published the paper entitled Une propriété charactéristique des algèbres booleiènnes, in which a distributive lattice containing fïrst and last element is a Boolean algebra if, and only if, every prime ideal is maximum, see Nachbin (1947).

Also in 1947, at the suggestion of António Monteiro, the Department of Mathematics of FNFi hired L. Nachbin as Regent professor of the Mathematical and Superior Analysis, with a one-year work contract, as was usual at the time. Between late 1947 and early 1948, and at the suggestion of António Monteiro, L. Nachbin held a competition for livre-docente of Mathematical Analysis and Superior in the Department of Mathematics of FNFi and was approved. For this contest L. Nachbin presented the thesis entitled Combinação de Topologias Pseudo - Metrisáveis e Metrisáveis, see Nachbin (1947); a very current subject for the mathematics of the 1940s. At that time Topology was an important field of scientific research in Europe and the United States of America. L. Nachbin taught in the didactic test of this contest a class entitled: The Notion of Abstract Space by Hilbert.

In this way, the authors of L. Nachbin were expressed in (SILVA DIAS; HÖNIG; MEDEIROS, 1994, p. 173):

"[...] In the Department of Mathematics of the Faculdade Nacional de Filosofia da Universidade do Brasil in Rio de Janeiro he found a stimulating Mathematical atmosphere. He had the opportunity of joining an academic staff to which belonged the Italian Mathematicians Gabriele Mammana (a former student of Mauro Picone) and Luigi Sobrero (a former student of Levi-Civita) [...]". 
L. Nachbin said the following about A. Monteiro:

"[...] It suffices to express globally my indebtedness to Monteiro's influence when I was young and inexperienced, from the mathematical, psychological and political viewpoints, an occasion in which Monteiro granted me his valuable advice, protection and initiative [...]". (NACHBIN, 1980, p. xvi).

After gaining the livre-docência, in the first half of 1948, L. Nachbin earned a scholarship from the USA State Department for a postdoctoral fellowship at the University of Chicago from October 1948 to September 1949. In 1949 he won a scholarship from the Guggenheim Foundation for the period from October 1949 to September 1950 to continue his studies at the University of Chicago. At this stage of the post World War II period, the University of Chicago was, and continues to be, one of the major centers of mathematical research and research in the West. In that institution they worked and are currently working, important and creative mathematicians. At that time they were in the institution doing advanced studies and teaching various mathematical courses, among which we quote M. M. Peixoto (1921-2019) and J. Dieudonné.

At that time, the head of the Mathematics Department at FNFi/UB was Professor José da Rocha Lagoa, who did not renew L. Nachbin's employment contract while he was at the University of Chicago. For this reason, Professor Joaquim da Costa Ribeiro, who was head of the Department of Physics of FNFi and Professor Catedrático of General and Experimental Physics of that Department, proposed that L. Nachbin be transferred to the Department of Physics of FNFi where he became a professor contracted until the transfer of the University of Brazil to the Island of Fundão in the year of 1964.

It should be recalled that initially L. Nachbin was an assistant professor in the Department of Mathematics at ENE/UB. With the reform of the Brazilian university made by the federal government in the late 1960s and early 1970s, the Institute of Mathematics of the University of Brazil (IM/UB, in Portuguese) was created. For this new unit of the UB were transferred the professors who belonged to the Departments of Mathematics of the different Faculties and Schools of UB. And with the transformation of UB into UFRJ in 1965, the IM/UFRJ was created where L. Nachbin was finally transferred.

Before arriving at Faculty of Philosophy, Sciences and Letters of the University of São Paulo (FFCL/USP, in Portuguese) in January 1945, as visiting professor, A. Weil had introduced uniform spaces or uniform structures; see Weil (1937) and Bourbaki (1951), which later became the basic themes for some of the works of L. Nachbin in topology. At that time J. Dieudonné, who was later employed as a visiting professor in the Department of Mathematics at FFCL/USP, was interested in field theory and in topological vector spaces 5 . The contact of L. Nachbin with both influenced later his interest for the studies in the subjects mentioned above.

\footnotetext{
${ }^{5}$ Between 1946 and 1947 A. Weil and J. Dieudonné were working at USP as visiting professors at the FFCL / USP. They were prominent members of the N. Bourbaki group.
} 
L. Nachbin also received strong scientific influence from other mathematicians who had been at FNFi as visiting professors in the 1940s and 1950s. For example, in 1947 Marshall Stone taught a three-month course at FNFi on Rings for Continuous Functions. This course which was attended by L. Nachbin exerted a strong influence on his work in theory of approximation. See Nachbin (1949b) and Nachbin (1950).

In the year $1950 \mathrm{~L}$. Nachbin participated in the International Congress of Mathematicians - ICM/1950, which was held in Cambridge, USA. In this event he made a brief communication entitled $O n$ the continuity of positive linear transformations, see Nachbin (1950b), on results obtained in general topology. We assume that these were their most important results produced in general topology. Subsequently, L. Nachbin expanded these results in the form of two papers, (NACHBIN, 1952, 1970).

In the year 1950, there was a competition in the Department of Mathematics of FNFi for the Chair (Cátedra) of Mathematical Analysis and Superior, whose interim Professor was José Abdelhay (1917-1996). Leopoldo Nachbin enrolled in this contest, and presented the thesis entitled Topologia e Ordem, University of Chicago Press, 1950. This work was written when L. Nachbin conducted a research internship at the University of Chicago.

Some information about the Topologia e Ordem work. Before traveling to the University of Chicago in 1948, L. Nachbin had for some time worked on the idea of combining two structures with which he had worked: topology and order. In working with these structures he has introduced them into the ordered topological space theory that generalizes the topology in the sense that if the order is discrete, that is, there are no two distinct comparable elements, and then its result becomes a known topology theorem, (NACHBIN, 1948a, 1948b, 1948c).

During his stay at the University of Chicago, L. Nachbin extended the results obtained in the above mentioned notes and transformed them into the work (later published in book form) Topology and Order that presented as a thesis in 1950 to the quoted above contest. In this text L. Nachbin generalizes the classic result of the Pavel Urysohn lemma's ${ }^{6}$, (NACHBIN, 1950a, Theorems 1 and 2) ${ }^{7}$.

The date of registration of L. Nachbin in the above mentioned competition marks the beginning of the intensification of the radicalization of some professors against $\mathrm{L}$. Nachbin in the Department of Mathematics of FNFi. The professors who supported José da Rocha Lagoa did not want L. Nachbin to be enrolled in the contest; claimed that he was not a mathematician, so he could not enter the competition for the Cátedra of Mathematical Analysis and Superior of the Department of Mathematics of FNFi. It should be remembered that L. Nachbin was a livre-docente in Mathematical Analysis by FNFi/UB.

Concerning this internal dispute, let us see what Luis Adauto da Justa Medeiros tells us in Preface to the Second Edition of Silva's book (2013, p. xi):

\footnotetext{
${ }^{6}$ Urysohn's lemma states: "A topological space is normal if and only if any two closed separated subsets can be separated by a continuous function."

7 The results of these two theorems were used by G. Mehta in Mathematical Economics to give new demonstrations to the theorems of Gérard Debreu, winner of the Nobel Prize in Economics in 1983. See G. Mehta in Topological ordered spaces and utility functions. Internat. Econom. vol. 18, p. 779-782, 1977.
}

RBHM, Vol. 19, no 38, p. 83-103, 2019 
"The contest had an impasse from an administrative point of view. We believe that this impasse had negative consequences in the development of Mathematics in the FNFi of UB. Academic competition became an administrative struggle, when consciences were they confranced and the consequences were malignant”. (SILVA, 2013, p. Xi).

We suppose that the real reason why the professors who supported José da Rocha Lagoa (who did not want L. Nachbin's entry in the contest at issue), did not want L. Nachbin's enrollment in the above mentioned competition to be another and not only by the fact that he was not graduated in Mathematics. Due to the high qualification and scientific prestige of L, Nachbin, we are of the opinion that the professors who supported José da Rocha Lagoa were against his registration in the contest, because they were afraid that he would win the first place, when the contest was made. As there was only one vacancy, the acting Catedrático would be left out, and L. Nachbin would assume the Cátedra of Mathematical Analysis and Superior of the Department of Mathematics of the FNFi. At that time L. Nachbin already enjoyed great scientific prestige along with the dynamic international mathematical community of the post World War II period.

It should be remembered that when L. Nachbin was pursuing a post-doctorate internship at the University of Chicago, he was offered a good academic position in that institution; L. Nachbin did not accept because he wanted to work in Brazil and here contribute to the development of Mathematics, as well as guide talented young students to studies and research in Mathematics ${ }^{8}$.

The above competition had an insoluble impasse. Professors on both sides, against and in favor of the acceptance of the registration of L. Nachbin in the contest, in addition to appealing to the Congregation of the FNFi and to the University Council of UB, also made to the Federal Court. As a result, the competition was only held 22 years later, that is, in 1972, during IM/UFRJ and for the position of Full Professor. We remind that, with the reform of the Brazilian university, the position of Catedrático was extinguished and to replace him was created the position as Full Professor. L. Nachbin held the competition, was approved and appointed in 1972 as Full Professor of the Department of Algebra, Analysis and Geometry of IM/UFRJ ${ }^{9}$.

In 1951 Leopoldo Nachbin taught a course for students (Luis Adauto Medeiros was one of those students) graduated from FNFi on theory of distribution, a very new subject at the time and which was developed in the 1940 s by the French mathematician Laurent Schwartz ${ }^{10}$. This topic was part of the program of the discipline of Mathematical Physics of the Chair of Mechanics, of the FNFi.

${ }^{8}$ About the impasse of the competition, in 1952 the mathematicians J. Dieudonné, C. Ehresmann and L. Schwartz sent a letter to the Rector of the UB suggesting a solution to the problem. A suggestion that was not followed. See (SILVA, 2013, Appendix, p. 487).

${ }^{9}$ In 1964 all the interim were made effective in their positions. Thus, the interim Professors were made Full Professors.

${ }^{10}$ In 1950 L. Schwartz was one of the winners of the prestigious Fields Medal Award for developing Theory of Distributions, a new notion of generalized function motivated by the Dirac delta function of theoretical physics. Theory of Distributions has strong use in several subareas of Mathematics, such as PDE, Topology and Fourier Analysis, and in theoretical Physics. A distribution is defined as a continuous linear transformation of a test 
As of 1945, the Mathematics Department of FNFi contracted as visiting professors, besides António Monteiro, three American mathematicians who were: A. A. Albert, Marshall Stone and W. Ambrose and, in the early 1950s, hired three French mathematicians which were: J. Dieudonné, L. Schwartz and C. Ehresmann. Leopoldo Nachbin became friends with these mathematicians and, as a result of this friendship and participation in the courses they taught, he spent between 1947 and 1949 to take an interest in the study of the Theory of Approximation.

In his early studies on Theory of Approximation, while at the University of Chicago, L. Nachbin obtained, in 1949, a result analogous to the Weierstrass-Stone Theorem, for differentiable functions. In this work L. Nachbin presents his characterization of dense subalgebras of differentiable functions. See Nachbin (1949).

L. Nachbin also approached the French mathematician A. Weil when he was hired as a visiting professor in 1945 by the Department of Mathematics at FFCL/USP, as mentioned above. This mathematician stimulated L. Nachbin to study the Uniform Spaces and Vector Topological Spaces. The results of this stimulus can be observed by the reader in L. Nachbin's work on these topics.

In 1949 L. Nachbin published the paper On strictly minimal topological division rings. Bull. Amer. Math. Soc. vol. 55, p. 1128-1136, 1949, work that caught the attention of mathematician Irving Kaplansky of the University of Chicago. In the introduction to the paper so expressed L. Nachbin:

"In this note we shall determine the widest classes of topological division rings that can be used as scalar domains of topological vector spaces so as to preserve these important propositions. The results thus obtained generalize part of the recent work of J. Braconnier [2] and I. Kaplansky [5]. In a subsequent paper we shall apply these results to other related questions.

A topological ring is a ring endowed with an admissible topology, that is, a Hausdorff topology on the ring with respect to which the ring operations $x+y,-x, x y$ are continuous. A topological vector space is a vector space over a topological division ring endowed with an admissible topology, that is, a Hausdorff topology on the vector space with respect to which the vector space operations $x+y, \lambda x$ are continuous. Throughout this note we shall understand the notion of completeness and completion for these topological systems in the sense formulated by A. Weil [8] (see also Bourbaki [l]". (NACHBIN, 1949).

About this paper by L. Nachbin was expressed by I. Kaplansky: "Here, the marks of your style are well displayed: scholarship, clear exposure and progress until definitive

function into the complex numbers $\mathrm{C}$. This means that a distribution is a transformation that associates every test function with a complex number. To the reader interested in technical information on the theory of distributions, we suggest reading the texts of Honig (s.d.) and (MEDEIROS, MIRANDA, 2000, p. 10-21). For information with less technicality see the article (BARANY; PAUMIER; LÜTZEN, 2017). Information on the prehistory of distribution theory, see the book by Lützen (1982).

RBHM, Vol. 19, no 38, p. 83-103, 2019 
results are obtained". During his tenure at the University of Chicago, which culminated in the year 1950, L. Nachbin obtained important results in Functional Analysis that resulted in the publication of the paper that we believe to be the most important of the results obtained in his professional activity.

This paper was also, by the information we have, his most quoted work by the international mathematical community, and he was quoted 283 times according to Math SciNet in related works. The paper deals with the Hahn-Banach Theorem with vector values. It is the following paper: Theorem of the Hahn - Banach type for linear transformations. Trans. Amer. Math. Soc., vol. 68, p. 28-46, 1950. See Nachbin (1950).

The result obtained by L. Nachbin in this paper generalizes the well-known HahnBanach theorem for linear transformations. Let $\mathrm{E}$ be a Banach space on $\mathrm{K}$, and $\mathrm{M}$ a subspace of E. The Hahn-Banach theorem states that: each continuous linear functional $\varphi$ : $\mathrm{M} \rightarrow \mathrm{K}$ admits a continuous linear extension, $\widetilde{\varphi}: \mathbb{E} \rightarrow \mathbb{K}$ with the same standard. Result that is found in the mathematical literature concerning Functional Analysis and applications and in Topological Vector Spaces.

Before the publication of this paper, L. Nachbin published a paper in the form of a note containing six theorems, the purpose of which, we suppose, would be to foretell mathematicians for the important result which forms part of the content of his paper. That note was the paper entitled On the Hahn-Banach Theorem. An. Acad. Bras. Ciênc., tomo. 21, no. 2, p. 151-194, 1949. In the introduction of this paper, after quoting Hahn-Banach's theorem for the field R, thus was expressed L. Nachbin:

"The extension of continuous linear transformations between two real normed spaces was already studied by several authors and since long it was recognized that this problem has close connection with the question of the existence of projection of norm one of a normed space onto a vector subspace, and moreover that. The nature of the space where the transformations take their values is much more important that of the space where they have to be defined.

A known problem consists in giving a necessary and sufficient condition which refers only to the space where the transformation takes its values and does not involve the transformation itself or the space where it is to be defined, for the possibility of extending a transformation without disturbing its linearity, continuity and norm. In the present note we shall indicate some results related to this problem". (NACHBIN, 1949).

In the paper A theorem of the Hahn-Banach type for linear transformations, cited above, L. Nachbin studied the following problem:

"Let $F$ be a real normed space. Decide when it is true that it is always possible to extend any continuous linear application $f$ in any vector subspace $S$ from an arbitrary real $E$ space with values in $F$ to a continuous linear application $f$ in $E$ with values in $F$ preserving the norm of $f^{\prime \prime}$. 
In the introduction to this paper, this was expressed by L. Nachbin:

"Every continuous linear functional defined on a vector subspace of a real normed space can be extended to the whole space so as to remain linear and continuous, and with the same norm. The extension of continuous linear transformations between two real normed spaces has been studied by several authors and for a long time it has been recognized that this problem has a close connection with the question of the existence of projections of norm one, and moreover that the nature of the space where the transformations take their values is much more important than that of the space where the transformations have to be defined. It is not known, as far as we can say, what are the precise conditions for the possibility of extending a transformation without disturbing its linearity, continuity, and norm. In this paper we shall give a necessary and sufficient condition, which refers only to the space where the transformation takes its values and does not involve the transformation itself or the space where it is to be defined, for such an extension to be possible: the condition is expressed in terms of a certain "binary inter-section property" of the collection of spheres of the normed space (see Theorem 1). After that we proceed to the study of the structure of real normed spaces whose collections of spheres have this property. A first step in this direction is given by the theorem asserting that these normed spaces (provided they contain at least one extreme point in the unity sphere) are simply those that can be made into complete vector lattices with order unity in such a manner that the norm derived from the order relation and the order unity in the natural way is identical to the given norm (see Theorem 2, and Theorem 3 for the finite-dimensional case). In this connection we point out a conjecture which we have not been able to settle, namely that, if the collection of spheres of a normed space has the binary intersection property, then its unity sphere must contain an extreme point. By using some results of S. Kakutani and M. H. Stone, we establish the connection between the normed spaces having the binary intersection property and the spaces of real continuous functions over certain compact Hausdorff spaces (see Theorem 4), or the complete Boolean algebras (see Theorem 6).

Besides the problem which we consider in this paper, it would be interesting to investigate in the same direction the extension of transformation with preservation of linearity and continuity, but not necessarily of the norm. In this paper we have restricted ourselves to real normed spaces. It is known, as a consequence of the real case, that the Hahn-Banach theorem holds good for normed spaces with the complex numbers or quaternions as (Archimedean) scalars. The Hahn-Banach theorem for normed spaces over fields with (nonarchimedean) valuations has also been studied. It would be interesting to examine the extension of 
linear continuous transformation in these more general situations". (NACHBIN, 1950).

The result obtained by L. Nachbin, in the case of spaces in R, characterizes the spaces of Banach $\mathrm{F}$ with the extension property. This fact is demonstrated by the following:

"Theorem. Let $F$ be a Banach space, the following conditions are equivalent:

a) Given a Banach space $E$ and a subspace $M$ of $E$, each operator

$T \in L(M ; F)$ admits an extension $\hat{T} \in L(E ; F)$ such that $\|\hat{T}\|=\|T\|$.

b) Whenever $F$ is a subspace of a Banach $G$ space, there exists a norm one projection of $G$ over $F$.

c) F has the property of the binary intersection, that is, a collection of closed balls of $F$ has non-empty intersection, whenever each pair of balls in the collection has no non-empty intersection.

d) There is a very compact Hausdorff compact space $X$, such that $F$ is isometrically isomorphic to $C(X)$ '”.

In addition to proving the equivalence of conditions a), b) and c), L. Nachbin also proved that condition d) always implies condition c) and that condition c) implies condition d), provided that the closed unit ball of $\mathrm{F}$ has at least one extreme point ${ }^{11}$.

In the paper L. Nachbin thanks A. A. Albert and Marshall Stone of the University of Chicago for the encouragement given to pursue his research in search of the results he finally obtained.

We will mention only two papers related to the result obtained by L. Nachbin mentioned above, which mention it. They were the works of Day (1973) and Lotz (1975).

L. Nachbin also conjectured in Nachbin (1950) that if F is a reflective Banach space endowed with the property of the binary intersection, then the closed unitary sphere of $\mathrm{F}$ has at least one extreme point. In a note published in 1962, in the Annals of the Brazilian Academy of Sciences - ABC, he proved his conjecture, see Nachbin (1962b).

In the above note and which was published in the Annals of ABC, L. Nachbin states and demonstrates the following:

"Théorème. E étant un espace vectoriel topologique réel localement convexe séparé, si $\boldsymbol{A}$ est une partie convexe bornée et fermée de $\boldsymbol{\varepsilon}$ telle que la collection des $\lambda A+x$, pour $\lambda>0$ réel et $x \in \mathcal{E}$, ait la propriété d'intersection binaire, alors $A$ est l'enveloppe fermée convexe de l'ensemble de ses points extrémaux'.(NACHBIN, 1962b).

\footnotetext{
${ }^{11}$ D. B. Goodner in an article entitled: Projections in normed linear spaces. Trans. Amer. Math. Soc. vol. 69, no. 1, p. 89-108, 1950, also proved, independently of L. Nachbin, the equivalence of conditions a), b), c) of the Theorem cited. This paper condenses the main results obtained by the author in his doctoral thesis defended at the University of Illinois under the guidance of M. Day.
} 
In 1953 J. Dieudonné proposed to the international mathematical community the following problem: to decide whether all tone space would necessarily be bornological, see Dieudonné (1953). In 1954 L. Nachbin published work results containing a remarkable characterization of Tones or Bornological spaces of continuous functions, see Nachbin (1954) that solved the problem proposed by J. Dieudonné. He solved this problem in its negative form. These results were obtained, by L. Nachbin, independently and simultaneously to the results on the same subject obtained by the Japanese Mathematician T. Shirota, see Shirota (1954).

The publication of this paper by L. Nachbin in Proc. Nat. Acad. Sci, in the year 1954, was sponsored by the mathematician A. A. Albert. In this paper L. Nachbin has demonstrated the following:

"Theorem. Let X be a completely regular Hausdorff space, and consider $C(X)$ provided with the compact-open topology.

a) $C(X)$ is tone if and only if, for each closed but not compact subset $A$ of $X$, there exists a function $f \varepsilon C(X)$ which is not limited to $A$;

b) $C(X)$ is bornological if and only if, $X$ is filled". (NACHBIN, 1954).

By using in the proof of the theorem, existing results in the mathematical literature, L. Nachbin showed that there are spaces that check for condition a), but are not full; a fact that solves, in the negative, the problem proposed by J. Dieudonné.

L. Nachbin was invited by the scientific committee of the International Congress of Mathematicians 1962 (ICM/1962) as one of the invited speakers to talk about his research during the ICM that was held in 1962 in Stockholm - Sweden. This was the first time a Brazilian mathematician was invited to speak at ICM. His lecture was on: Résultats récents et problèmes de nature algébrique in théorie de l'approximation. (NACHBIN, 1962). 
Figure 1. Leopoldo Nachbin. Photo courtesy of Comp. Appl. Math.

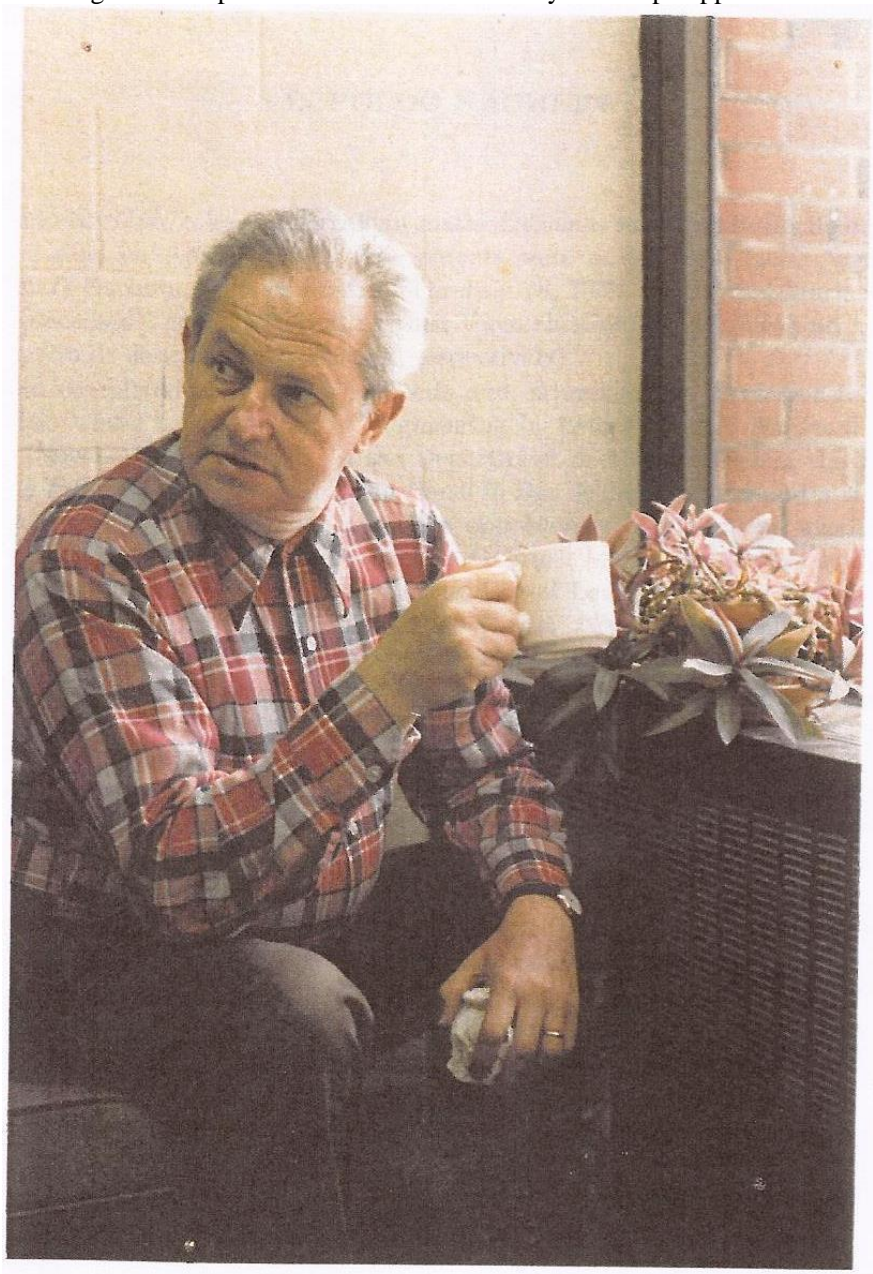

Leopoldo Nachbin 1922-1993

Photo taken at the University of Rochester in the 1980s.

\section{Final Considerations}

In addition to being an excellent and creative mathematician, another of $\mathrm{L}$. Nachbin's characteristics was to help talented and promising mathematical students who sought him out; to help them he used his prestige with the international mathematical community to write letters to excellent foreign universities recommending Ph.D. students in 
Mathematics. Another of its characteristics was the encouragement and support for the creation of new centers of excellence in Mathematics in some states of Brazil, especially in the city of Rio de Janeiro.

L. Nachbin, an elite scientist, has published works in the following sub-areas of Mathematical Analysis: Order, Topology, Harmonic Analysis, Topology and Order, Topological Vector Spaces, Orderly Topological Vector Spaces, Approximation Theory, Holomorphy. In this context he published relevant results in: Continuous Function Spaces, Weighted Approximation of Continuous Functions, Holomorphy in Infinite Dimension, Approximation of Differentiable Functions. Among the articles published by him on Holomorphy in Infinite Dimension, the works in which L. Nachbin introduced the topologies $\tau_{\tilde{\omega}}$ e $\tau_{\tilde{\sigma}}$ were the ones that had the greatest repercussion in the international mathematical community. But his work of greatest impact in this community was the paper entitled: Theorem of the Hahn-Banach type for linear transformations. Trans. Amer. Math. Soc., vol. 68, p. 28-46, 1950. L. Nachbin actively participated in the emerging dynamics of scientific activities that involved the international mathematical community of the post World War II period.

With elite scientists, we want to refer to those who have produced and continue to produce important and relevant scientific works that impact the area of science in which they work. They are people who can tell their disciples, and not disciples, what is important to be worked for the advancement of science at a given moment.

We are of the opinion that the period from 1947 to the year 1965 marks the most productive phase, and the period between 1949 and 1954 marks the most creative phase in terms of scientific research by L. Nachbin. In these periods he published 58 scientific works (papers and books) and participated in ICM 1950 and ICM1962.

At the invitation of the French mathematician Laurent Schwartz, L. Nachbin spent the period from October 1961 to September 30, 1963, at the Faculty of Sciences of the University of Paris, as visiting professor. In 1967 L. Nachbin took over the post of George Eastman Professor of Mathematics at the University of Rochester, USA. This chair of the Mathematics Department of the University of Rochester was created especially for him. In this phase, L. Nachbin divided the academic year, spending six months in Brazil and six months at the University of Rochester.

We emphasize to the reader that we are not mentioning the various stays since 1948 by L. Nachbin as visiting professor at universities in several countries, among which we cite: France, the United States of America, and Latin American countries.

L. Nachbin was one of the founders in 1946, and one of the researchers of the Scientific Technical Nucleus of Mathematics - NTCM of the Getúlio Vargas Foundation FGV, organ that was headed by Lélio Gama. The aim of the NTCM was to coordinate scientific research in mathematics, starting in Brazil, and to maintain a broad communication with math centers in Latin America, the United States, Portugal, Italy and France.

L. Nachbin was also one of the founders, in 1948, of the Brazilian Center for Physical Research - CBPF and one of its full time researchers. He was one of the founders, in 1951, one of the organizers and one of the researchers of the Institute of Pure and 
Applied Mathematics - IMPA (in Portuguese). In this institution, he and Luis Adauto da Justa Medeiros, began to organize their postgraduate and library (IBBD/CNPq, 1969, 115).

In 1967 Van Nostrand published the book entitled Elements of Approximation Theory, which contains lecture notes on courses on Topological Vector Spaces taught by L. Nachbin at the Faculty of Sciences of the University of Paris in 1962, and at the University of Rochester in 1964 .

In the 1970s and early 1980s, he encouraged some of his former students and colleagues to hold various scientific events on: Approximation Theory, Holomorphy in Infinite Dimension, Functional Analysis, of which he participated in conferences.

Among these events we mention: Colloquium of Analysis, which was held in IM/UFRJ in August 1972 and was coordinated by Mário de Carvalho Matos. The Annals of this event, entitled Analyse Fonctionnelle et Applications, were edited by L. Nachbin in Hermann, Paris, 1975. Functional Analysis and Applications. Symp. Analysis. Performed at UFPE in July 1972. The Proceedings of this event were edited by L. Nachbin in Lectures Notes in Math. 384, Berlin: Springer, 1974. International Symposium on Infinite Dimensional Holomorphy. Performed at UNICAMP in August 1975. The proceedings of this event were edited by Mário C. de Matos in North Holland Math. Stud. 12, Amsterdam, 1977. Seminar on Functional Analysis, Holomorphy and Approximation Theory. Held in August 1978 at UFRJ. The Proceedings of this event were edited by Silvio Machado in Lectures Notes in Math. 843, Berlin, Springer, 1981. Complex Analysis, Functional Analysis and Approximation Theory. Held in July 1984 at UNICAMP. The editor of the Annals of this event was J. Mujica, North Holland Math. Stud. 125, Amsterdam, 1986.

Until 1980, L. Nachbin directed 21 doctoral theses in Brazil and abroad in the following areas: Functional Analysis, Holomorphy, Approximation Theory and Mathematical Physics. For the list of works published by L. Nachbin, which are 111 works, we suggest (MAST, 1997) and (HORVÁTH, 1986).

In 1967, together with Heitor Gurgulino de Souza of the OEA, L. A. da J. Medeiros, L. Nachbin was one of the founders of the Latin American School of Mathematics - ELAM, an event held every two years in a country other than Latin America. In 1950 L. Nachbin was elected a member of the Brazilian Academy of Sciences - ABC. In 1983 he was elected a member of the newly founded Academy of Sciences of Latin America.

The last works of L. Nachbin produced between the second half of the 1980s and the beginning of the 1990s was in:

Convex Sets. In this sub-area of the Analysis, L. Nachbin takes up studies by L. Schwartz (Schwartz, 1973), B. Fuchssteiner and W. Lusky, (Fuchstein and Lussky, 1981), who considered abstract convex cones that are not necessarily subsets of a vector space. Convex cones and convex sets are introduced without assuming that they are vectors, that is, they are convex sub-cones and convex subsets of real vector spaces. A convex cone is vector if and only if it satisfies the cancellation rule for convex cones. A convex set is vector if and only if it satisfies the cancellation rule for convex sets. L. Nachbin gives in Proposition 7 and Proposition 10, from (NACHBIN, 1993), below reproduced, the demonstration of what is in fact an example of the construction of the celebrated group of Grothendieck, (GROTHENDIECK; DIEUDONNÉ, 1971). 
"Proposition 7. Let $C \neq \Phi$ be a convex cone. There are a real vector space $E$ and a convex cone map $f: C \rightarrow E$ such that $E=f(C)-f(C)$, and $f$ is larger than any convex cone $g: C \rightarrow F$, where $F$ is a real vector space such that $F=g(C)-g(C)$. Moreover, $f: C \rightarrow E$ is essentialy unique in the sense that, if $f_{i}: C \rightarrow E_{i}(I=1,2)$ are two choices for $f: C \rightarrow \mathrm{E}$, then $f_{1} \sim f_{2} *$

For the demonstration of Proposition 7 the author uses content that is in Remark 4, before Proposition 7, which is as follows:

"Remark 4. Let $C$ a convex cone without zero. We get a convex cone with zero $C_{o}$ in a natural way as fellows. Fix a point $0 \emptyset C$. Set $C_{o}=C$ $\cup\{0\} . \quad$ Extend $\left(x_{1}, x_{2}\right) \in C X C \mapsto x_{1}+x_{2} \in C,(\lambda, x) \in \mathbb{R}_{+}^{*} X C \mapsto \lambda x \in$ $C$ to $\left(x_{1}, x_{2}\right) \in C_{o} X C_{o} \mapsto x_{1}+x_{2} \in C_{o},(\lambda x) \in \mathbb{R} X C_{o} \mapsto \lambda x \in C_{o}$ by defining $0+0=0, x+0=0+x=x, 0.0=0,0 . x=0, \lambda .0=0$ for $\lambda$ $\in \mathbb{R}_{+}^{*}, x \in C$. Then $C_{o}$ is a convex cone with zero containing $C$ as a convex subcone". (NACHBIN, 1993, p. 469).

The author begins the demonstration of Proposition 7 thus: "We may assume that C has zero. (Remark 4)".

For the demonstration of Proposition 7, see Nachbin (1993, p.469).

"Proposition 10. Let $C ¥ \Phi$ be a convex cone. If $E$ is a real vector space, and the convex cone map $f: C \rightarrow E$ is injective, then $C$ satisfies the cancellation rule for convex cones. Conversely, if $C$ satisfies this rule, then $f: C \rightarrow E$ of Proposition 7 is injective. Hence a convex cone is vectorial if and only if it satisfies the cancellation rule for convex cones".

For the demonstration of Proposition 10, see Nachbin (1993, p.470).

Approximation Theory. In this section of the Analysis, L. Nachbin resumed studies carried out in the 1960s on a weighted approximation. In Nachbin (1991), he comments on a weighted approximation of differentiable functions, a topic approached by Zapata (1973) and, demonstrates two lemmas. In Lemma 1, it gives a condition for a weight to be $\mathrm{C}^{\mathrm{m}}$ fundamental in R, in terms of a fundamental C - weight in R. In Lemma 2, L. Nachbin gives a condition for a weight to be $\mathrm{C}^{\mathrm{m}}$ - fundamental in $\mathrm{R}$ in terms of weights that are $\mathrm{C}^{\mathrm{m}}$ fundamental in R.

As informed by prof. dr. Dicesar Lass Fernadez, in the subarea Qualitative Approximation Theory, prof. dr. João Bosco Prolla was the main continuator of L. Nachbin's works. He and L. Nachbin worked with this subarea of Mathematical Analysis. 
work.

Information about the ratings used above. was the main continuator of Nachbin's

$\mathrm{C}^{\mathrm{m}}\left(\mathrm{R}^{\mathrm{n}}\right)$ denotes the algebras of all functions $\mathrm{f}$ over $\mathrm{R}^{\mathrm{n}}$ for which the partial derivatives $\partial^{\alpha}$ f exist and are continuous when $\alpha \in N_{m}^{m}$. R denotes the field of the real.

$N_{m}^{m}$ denotes the set of all multi-indices $\alpha=\left(\alpha_{1}, \ldots, \alpha_{n}\right) \in N^{n}$ such that $|\alpha|=\alpha_{1}+\cdots$ $+\alpha_{\mathrm{n}} \leq \mathrm{m}, \mathrm{n} \geq 1, \mathrm{~m} \geq 0$, with $\mathrm{n}, \mathrm{m}$ integers.

Holomorphy. In this sub-area of the Analysis, L. Nachbin returns to developing ideas initiated and worked in 1986. This time he approaches the concept of uniform holomorphy and, more generally, demonstrates some of the results discussed in 1986, see Nachbin (1986). And also (MATOS; NACHBIN, 1992).

Probability. In this topic, L. Nachbin picks up studies he presented in a mini-course held at IMECC/UNICAMP (in Portuguese) in the summer of 1985 on probability theory and stochastic processes. See Nachbin (1987).

For summary technical information on the works of L. Nachbin, from the 1980s, in the subareas mentioned above, we suggest the reading of Horváth (1994).

We hope that the legacy, in the form L. Nachbin's contribution to modern mathematical analysis, will be visible in this text.

\section{Acknowledgement}

We are grateful to prof. dr. Luis Adauto da Justa Medeiros, emeritus professor at UFRJ, for suggesting us to write an article about L. Nachbin's professional life, focusing only on the period in which he worked at UB's FNFi and in the initial phase of IM/UFRJ until his retirement. Thanks also for the useful conversations we had during the preparation of the manuscript and for the reading of this text. We would also like to thank prof. dr. Dinamérico P. Pombo Jr, from the Institute of Mathematics and Statistics of the Federal Fluminense University (UFF, in Portuguese), for reading the text and suggestions. He was the last orienting of L. Nachbin in the IM/UFRJ doctoral program.

\section{References}

BARANY, M. J.; PAUMIER, A-S.; LÜTZEN, J. From Nancy to Copenhagen to the World: The internationalization of Laurent Schwartz and his theory of distributions. Hist. Math. vol. 44, no 4, p. 367-394, 2017.

BARROSO, J. A.; MATOS, M. C.; NACHBIN, L. On holomorphy versus linearity in classifying locally convex spaces. Infin. Dim. Holom. Appl. Proc. Int. Symp. UNICAMP, 1975, p. 31-74, 1977. (Zbl 0399.46034).

BOURBAKI, N. Topologie Generale. Paris: Herman \& Cia. Éditeurs, 1951. Chapitre II.

DAY, M. M. Normed linear spaces. Berlin: Springer-Verlag, 1973.

DIAS, C. L. da S.; HÖNIG, C. S.; MEDEIROS, L. A. da J. Leopoldo Nachbin. Comp. Appl. Math., vol. 13, no 3, p. 173-174, 1994.

DIEUDONNÉ, J. Análise Harmônica. Publicação nº 9, Rio de Janeiro: FNFi, 1952. Notas de aulas redigidas por J. Abdelhay. 
Recent developments in the theory of locally convex vector spaces. Bull. Amer. Math. Soc., vol. 59, p. 495-512, 1953.

FUCHSSTEINER, B.; LUSKY, W. Convex Cones. North - Holland Math. Stud. 56 Notas Mat. 82, Amsterdam, 1981.

GOMES, R. L. Homenagem a Leopoldo Nachbin. Gazeta de Matemática. Anos 34-35, nº 129-132, p. 7-11, 1973-1974.

GOODNER, D. B. Projections in normed linear spaces. Trans. Amer. Math. Soc., vol. 69, no 1, p. 89-108, 1950.

GROTHENDIECK, A.; DIEUDONNÉ, J. Eléments de géométrie algébrique I, Grundlehren Math. Wiss., 166, p. 236-246, 1971.

HÖNIG, C. S. Teoria das distribuições. São Paulo: IME/USP, s.d.

HORVÁTH, J. The life and Works of Leopoldo Nachbin, in BARROSO, J. A.(editor). Aspects of Mathematics and its applications. Elsevier Science Publishers B. V., 1986.

1994. The late works of Leopoldo Nachbin. Com. Appl. Math. vol. 13, n 3, p. 175 -188,

IBBD/CNPq. Notícias. Noticiário do IMPA. Rio de Janeiro: 1969.

LOTZ, H. P. Extension and liftings of positive linear mapping on Banach Lattices. Trans. Amer. Math. Soc., vol. 211, p. 85-100, 1975.

LÜTZEN, J. The Prehistory of the Theory of Distributions. Berlin: Springer-Verlag, 1982.

MACHADO, S. (Ed.). Functional Analysis, Holomorphy, and Approximation Theory. Lectures Notes Math. Berlin: Springer, 1981.

MAST. Arquivo Leopoldo Nachbin. Inventário Sumário. Rio de Janeiro: MAST, 1997.

MATOS, M. C. (Ed.). Infinite Dimensional Holomorphy and Applications. North-Holland Math. Stud. 12, Amsterdam, 1977.

MATOS, M. C.; NACHBIN, L. Reinhart domains of holomorphy in Banach spaces. Adv. Math. vol. 92, p. 266-278, 1992. (MR 93d:46069).

MEDEIROS, L. A.; MIRANDA, M. MILLA. Espaços de Sobolev (Iniciação aos Problemas Elíticos não Homogêneos). Rio de Janeiro: IM/UFRJ, 2000.

NACHBIN, L. Sobre a permutabilidade entre operações de passagem ao limite e de integração de equações diferenciais. An. Acad. Bras. Ciênc., tomo 13, p. 327-335, 1941.

208, 1942.

Un estensione di un lemma di Dirichlet. Atti. Accad. Italia Rend., vol. 3, p. 204 -

$-118,1947$.

Une propriété charactéristique des algèbres booleiènnes. Port. Math. vol. 6, p. 115

- Combinação de topologias pseudo - metrisáveis e metrisáveis. Notas de Matemática $\mathrm{n}^{\circ}$ 1, Rio de Janeiro: Universidade do Brasil, 1947.

. Sur les espaces topologiques ordonnés, C. R. Acad. Sci. Paris, vol. 226, p. 381382, 1948a. (MR, 9, 367).

. Sur les espaces uniformisables ordonnés. C. R. Acad. Sci. Paris, vol. 226, p. 547,

1948b. (MR 9, 367).

Sur les espaces uniformes ordonnés. C. R. Acad. Sci. Paris, vol. 226, p. 774-775, 1948c. (MR 9, 455).

Sur les algèbres denses de fonctions différentiables sur une variété. C. R. Acad.

Sci. Paris, vol. 228, p. 1549-1551, 1949. 
. On the Hahn-Banach Theorem. An. Acad. Bras. Ciênc., tomo 21, nº 2, p. 151-154, 1949b. (MR 11, 114).

. On strictly minimal topological division rings. Bull. Amer. Math. Soc. vol. 55, $\mathrm{n}^{\mathrm{o}}$ 12, p. 1128-1136, 1949c.

A theorem of the Hahn-Banach type for linear transformations. Trans. Amer. Math. Soc.,v. 68, p. 28-46, 1950. (MR 11, 369), (MR 32932 46.3X), (MathSciNet 0032932), (Zbl 0035.35402, v. 35, p.354).

. Topologia e ordem. Univ. Chicago Press, 1950a. Tese apresentada ao concurso para o cargo de professor Catedrático de Análise Matemática e Superior, FNFi/UB em 1950. (Zbl 0333. 54002).

- Some problems in extending and lifting continuous linear transformations. Proceedings of the International Symposium on Linear Spaces. Hebrew University of Jerusalem, 1950b.

. On a duality theorem for commutative groups. An. Acad. Bras. Ciênc., tomo 24, p.

137-142, 1952. (MR 16, 156).

. Topological vector spaces of continuous functions. Proc. Nat. Acad. Sci, vol. 40, $\mathrm{n}^{\circ} 6, \mathrm{p} .471-474,1954$.

. Résultats récents et problèmes de nature algébrique em théorie de l'approximation.

Stockholm: Proc. Internat. Congress Math., 1962. (MR 31, 548).

. Sur l'Abondance des Points Extrémaux d'un Ensemble Convexe Borné et Fermé.

An. Acad. Bras. Ciênc., vol. 34, p. 445-448, 1962b. (MR 26, 6736).

Elements of approximation theory. Rochester: University of Rochester, 1964.

Reimpresso em Van Nostrand Mathematical Studies, 14, 1967, D. Van Nostrand Company, New York.

. Sur les espaces vectoriels topologiques d'applications continues. C. R. Acad. Sci. Paris, vol. 271, p. 596-598, 1970. (MR 42, 6593).

Berlin: 1974.

.(Ed.). Functional Analysis and Applications. Lectures Notes in Math, vol. 384.

.(Ed.). Analise Fonctionelle et Applictions. Ed. Hermann: Paris, 1975.

. The influence of António A. Ribeiro Monteiro in the development of Mathematics

in Brazil. Port. Math., vol. 39, fasc. 1- 4, 1980.

A glance at holomorphic factorization and uniform holomorphy, Complex Analysis, Functional Analysis and Approximation Theory. North - Holland Math. Stud. 125. Notas Mat. 110, North- Holland, Amsterdam, p. 221-245, 1986, (MR 88h: 46085). . A profile of probability. Campinas: EdUNICAMP, 1987.

. On the weighted approximation of continuously differentiable functions. Proc. Amer. Math. Soc., vol. 111, p. 481—485, 1991. (MR 91f: 41028).

. Compact unions of closed subsets are closed and compact intersections of open subsets are open. Port. Math., vol. 49, n 4, p. 403-409, 1992.

. Convex cones and convex sets. Port. Math., vol. 50, no 4, p. 467-487, 1993. (Zbl 0808.46015).

. When does finite holomorphy imply holomorphy? Port. Math. vol. 51, no 4, p.525528, 1994. (Zbl 0870. 46030). 
Convex sets, convex cones, affine spaces and affine cones. Rev. Colomb. Mat. vol. 30, no 1, p. 1-23, 1996. (Zbl 0891.52001).

SCHWARTZ, L. Radon measures on arbitrary topological spaces and cylindrical measures. Tata Institute for Fundamental Research. Studies in Mathematics 6. Oxford University Press, 1973.

SILVA, C. P. da. Início e Consolidação da Pesquisa em Matemática no Brasil. 2a Ed., Rio de Janeiro: Editora Ciência Moderna, 2013.

SILVA DIAS, C. L. da; HÖNIG, C. S.; MEDEIROS, L. A. da J. Leopoldo Nachbin. Comp. Appl. Math., vol, 13, n 3, p. 173 -174, 1994.

SHIROTA, T. On locally convex vector spaces of continuous functions. Proc. Japan Acad., vol. 30, p. 294-298, 1954.

STONE, M. H. Applications of the theory of Boolean rings to general topology. Trans. Amer. Math. Soc., vol.41, p. 375 - 481, 1937.

PROLLA, J. B. Intersections of balls and approximation of vector valued functions. Aproximation Theory V, 1986. Aproximation Theory V. New York: Academic Press, p. 523-525, 1986.

. A generalized Bernstein approximation theorem. Mathematical Proceedings of the Cambridge Philosophical Society, v. 104, p. 317-330, 1988.

WEIL, A. Sur les Espaces à Structure Uniforme et sur la Topologie Générale. Paris: Herman \& Cia., Éditeurs, 1937.

ZAPATA, G. I. Bernstein approximation problem for differentiable functions and quasianalytic weighted. Trans. Amer. Math. Soc., vol. 182, p. 503-509, 1973.

Clovis Pereira da Silva
Professor aposentado - Departamento
de Matemática da UFPR
Curitiba - PR, Brasil.
E-mail: clovisps@ @ol.com.br

RBHM, Vol. 19, no 38, p. 83-103, 2019 